\title{
Hepatitis C Virus Infection and Metabolic Syndrome-A Community Based Study in Sohag University Hospital
}

\author{
Eman Ahmed Sabet and Ahmed Saad Allah Abd El Aal*
}

Faculty of Medicine, Sohag University, Egypt

\begin{abstract}
Background: Metabolic syndrome (MS) is a complicated disorder associated with a high risk of development of critical micro- and macrovascular complications. The extrahepatic manifestations of hepatitis $\mathrm{C}$ virus $(\mathrm{HCV})$ infection can include multiple metabolic consequences. However, the extent and severity of MS in HCV-infected patients have rarely been investigated in community based settings.

Objectives: To determine the difference in the prevalence and distribution of metabolic syndrome between HCVinfected patients and healthy controls, to identify whether HCV is considered a risk factor for metabolic syndrome in our community or not.

Methods: From January 2013 to December 2014, the authors retrospectively and prospectively studied 134 adult patients diagnosed to have HCV infection with age above 18, in Sohag area, Upper Egypt. Clinical profiles in terms of anthropometric data, MS components, and viral hepatitis markers, as well as Finnish Diabetes Risk Score (FINDRISC), were assessed.

Results: Three hundred and thirty-three adults (males: females=178: 155; mean age, $45.3 \pm 11.2$ years) were recruited. The prevalence of anti-HCV seropositivity was $40.2 \%$ (134/333). The prevalence of MS was higher in the HCV-infected individuals $(26.9 \%, 36 / 134)$ than in the control, uninfected subjects $(14.1 \%, 28 / 199, p=0.004)$. In terms of MS components, MS HCV-infected subjects had a higher waist circumference $(88.7 \pm 7.3$ vs. $85.4 \pm 4, p<0.001)$ and higher levels of fasting plasma glucose $(111.9 \pm 26.6$ vs. $102.5 \pm 20.4, p<0.001)$ than controls. Through the study the FINDRISC risk was increased in HCV- infected subjects, the very high risk score was $(4.5 \%$ vs. $0.0 \%, p<0.001)$ than controls. Multivariate logistic regression analysis proved that anti-HCV positivity was significantly associated with MS (odds ratio, 2.2; $p=0.004$ ).
\end{abstract}

Conclusion: HCV infection was associated with a higher prevalence of MS in our community. Determination of $\mathrm{MS}$ in patients with HCV infection could therefore be needed.

Keywords: Cirrhosis; Finnish diabetes risk score; Hepatitis C virus; HOMA; Insulin resistance; Lipid metabolism; Liver biopsy; Metabolic syndrome; NCEP; Obesity; Pathophysiology; Steatosis; Screening; Type 2 diabetes

\section{Introduction}

Hepatitis C virus (HCV) affects approximately 170 million people worldwide. More than $80 \%$ of patients with HCV infection progress into chronicity, $20-30 \%$ of patients with chronic hepatitis C progress to cirrhosis after 10-20 years of follow-up, and some develop hepatocellular carcinoma [1].

The highest Hepatitis C Virus (HCV) prevalence in the world occurs in Egypt at an estimated 12\% among the general population [2] and reaches $40 \%$ in persons 40 years of age and above in rural areas [3]. HCV Genotype 4 is the predominant genotype being isolated from up to $91 \%$ of HCV-infected persons in Egypt [4]. The origin of the HCV epidemic in Egypt has been attributed to intravenous schistosomiasis treatment in rural areas in the 1960s-70s [5].

Metabolic syndrome (MS) is a complicated disorder including clinical features such as; obesity, hyperglycemia, hypertension, dyslipidemia, and insulin resistance (IR). Atherosclerosis and type 2 diabetes mellitus (DM), as major consequences of MS, are critical, global health issues [6]. Current evidence suggests that the atherosclerotic process is regulated by intervening inflammatory mechanisms. IR, a key feature in the pathogenesis of MS, has been increasingly recognized as playing a key role in the inflammatory processes. A number of metabolic disturbances have been shown to be directly and indirectly associated with HCV infection. An association between HCV infection and lipid metabolism has been consistently reported [7].

Lower total cholesterol (TC), high-density lipoprotein cholesterol (HDL-C), low-density lipoprotein cholesterol (LDL-C) and triglyceride (TG) levels are commonly noticed in patients with chronic HCV infection (CHC), compared with normal subjects. Hepatic steatosis is a common histologic feature of $\mathrm{CHC}$ and is observed in $30-70 \%$ of patients [8]. Many factors are known to increase the risk of hepatic steatosis, including DM, hyperlipidemia, and obesity [9]. In addition to its hepatotropic characteristic, $\mathrm{HCV}$ infection is associated with the pathogenesis of IR, though the underlying biological mechanisms are diverse and multifactorial. Both experimental and clinical studies have shown that IR often emerges at a young age or during the early stages of histologic liver changes [10].

This study aimed to determine the difference in the prevalence and distribution of metabolic syndrome between HCV-infected patients

*Corresponding author: Ahmed Saad Allah, Faculty of Medicine, Sohag University, Egypt, Tel: +201006818903; E-mail: dr.infection@yahoo.com

Received March 20, 2015; Accepted July 23, 2015; Published July 27, 2015

Citation: Sabet EA, El Aal ASAA (2015) Hepatitis C Virus Infection and Metabolic Syndrome-A Community Based Study in Sohag University Hospital. J Diabetes Metab S13: 011. doi:10.4172/2155-6156.S13-011

Copyright: (C) 2015 Sabet EA, et al. This is an open-access article distributed unde the terms of the Creative Commons Attribution License, which permits unrestricted use, distribution, and reproduction in any medium, provided the original author and source are credited. 
and healthy controls, to identify whether HCV is considered a risk factor for metabolic syndrome in our community or not.

\section{Patients and Methods}

\section{Patient selection}

Our study was included 134 adult patients included both male and female with age above 18 years old, diagnosed to have HCV infection who treated in the outpatient clinics in Sohag University Hospitals in the period from January 2013 to December 2014. Scientific and Ethical committees at Sohag Faculty of Medicine approved the study. An informed written consent was obtained from all participants. Personal data (age, residency, occupation and special habits) were obtained from all participants.

\section{Study design}

All subjects underwent a 12-hour overnight fast before blood tests. Blood was analyzed for anti-HCV antibody, fasting plasma glucose (FPG), TC, HDL-C, LDL-C, TG, platelets count, and alanine aminotransferase (ALT) levels. Anthropometric data including body weight, height, body mass index and blood pressure were measured using standardized techniques. Research staff put a questionnaire covering medical history, drug history, possible parenteral risk history, and family history. In addition, Finnish Diabetes Risk Score (FINDRISC) to assess the risk of the development of type 2 diabetes mellitus and metabolic syndrome (MS). It showed that the FINDRISC has a good ability to predict undiagnosed prevalent T2DM and metabolic syndrome [11].

\section{Definition of MS}

Metabolic syndrome was defined based on the updated National Cholesterol Education Program Adult Treatment Panel III criteria for Asian-Americans, modified by the criteria of obesity proposed for Asians by the Steering Committee of the Regional Office for the Western Pacific Region of WHO [6,12]. This requires the presence of at least three of the following components: (1) waist circumference $>90$ $\mathrm{cm}$ in men or $>80 \mathrm{~cm}$ in women; (2) TG $>150 \mathrm{mg} / \mathrm{dL}$; (3) HDL-C $<40$ $\mathrm{mg} / \mathrm{dL}$ in men or $<50 \mathrm{mg} / \mathrm{dL}$ in women; (4) blood pressure $>130 / 85$
mmHg or current use of antihypertensive medications; (5) FPG>100 $\mathrm{mg} / \mathrm{dL}$ or use of oral antidiabetic agents or insulin.

\section{Laboratory analyses}

Hepatitis B surface antigen (HBs Ag) and anti-HCV antibody were detected using a third-generation, commercially available enzymelinked immunosorbent assay kit (AxSYM 3.0; Abbott Laboratories, Chicago, IL, USA). Detection of serum HCV RNA was performed using a standardized automated qualitative reverse transcriptionpolymerase chain reaction assay (COBAS AMPLICOR Hepatitis C Virus Test, version 2.0; Roche, Branchburg, NJ, USA). FPG, TC, TG, and ALT levels were measured using a multichannel autoanalyzer (Hitachi Inc., Tokyo, Japan).

\section{Statistical analysis}

Descriptive statistics were calculated for quantitative variables (mean, standard deviation, minimum and maximum) and for qualitative ones (absolute and percent frequencies). Mean of quantitative variables were compared by Student's t-test and those of qualitative ones have been compared by the chi-squared test. Univariate and multivariate logistic regression analyses were conducted to explore the factors that were independently associated with MS. The strength of association was presented as odds ratio (OR) and $p$ values. We used SPSS statistical software version 17 (SPSS Inc., Chicago, Illinois, USA), and significant results are considered when $\mathrm{P}$-value was $<0.05$, and highly significant when it was $<0.001$.

\section{Results}

a- Comparison between anti-HCV+ subjects and anti-HCVsubjects: 333 persons, 134 anti-HCV+ subjects $\{(88$ men $65.7 \%)$ and (46 women $34.3 \%)\}$ and 199 anti-HCV- subjects (controls) $\{(90$ men $45.2 \%)$ and (109 women $54.8 \%)\}$ were recruited in this study and their basic demographic characteristics are shown in Table 1.

The anti-HCV+ subjects had a higher waist circumference (WC) (Mean $\pm \mathrm{SD}=84.3 \pm 7.8, p<0.001)$ than anti-HCV- subjects. The prevalence of hypertension (14.2\% vs. $12.1 \%)$ was significantly higher in anti-HCV+ subjects compared with anti-HCV- subjects. There

\begin{tabular}{|c|c|c|c|c|c|}
\hline \multirow[t]{2}{*}{ Variables } & \multirow[t]{2}{*}{ All subjects $(n=333)$} & \multicolumn{3}{|c|}{ Anti-HCV } & \multirow[t]{2}{*}{$P$ value } \\
\hline & & \multicolumn{2}{|c|}{ Positive $(n=134)$} & Negative $(n=199)$ & \\
\hline Age (yr) & $45.3 \pm 11.2$ & \multicolumn{2}{|c|}{$43.5 \pm 12.4$} & $46.5 \pm 10.2$ & NS \\
\hline Male & $178(53.5 \%)$ & \multicolumn{2}{|c|}{$88(65.7 \%)$} & $90(45.2 \%)$ & NS \\
\hline DM History & $24(7.2 \%)$ & \multicolumn{2}{|c|}{$10(7.5 \%)$} & $14(7 \%)$ & NS \\
\hline HTN History & $43(12.9 \%)$ & \multicolumn{2}{|c|}{$19(14.2 \%)$} & $24(12.1 \%)$ & NS \\
\hline $\mathbf{W C}(\mathrm{cm})$ & & 84.3 & \pm 7.8 & $81.1 \pm 3.79$ & $<0.001$ \\
\hline Weight (kg) & & 80.1 & \pm 9.1 & $78.7 \pm 6.1$ & NS \\
\hline BMI $\left(\mathrm{kg} / \mathrm{m}^{2}\right)$ & & 27.2 & \pm 3.3 & $26.9 \pm 2.3$ & NS \\
\hline Platelets $\left(\times 10^{3}\right)(\mathrm{k} / \mathrm{ul})$ & & 258.9 & \pm 62.3 & $272.8 \pm 65.1$ & 0.049 \\
\hline ALT $(I U / I)$ & & \multicolumn{2}{|c|}{$35.8 \pm 16.6$} & $27.9 \pm 12.4$ & $<0.001$ \\
\hline FPG (mg/dL) & & \multicolumn{2}{|c|}{$92.8 \pm 19.04$} & $86.1 \pm 12.73$ & $<0.001$ \\
\hline $\mathrm{HDL}(\mathrm{mg} / \mathrm{dL})$ & & \multicolumn{2}{|c|}{$52.2 \pm 15.7$} & $56.7 \pm 12.7$ & 0.004 \\
\hline LDL & & \multicolumn{2}{|c|}{$85.4 \pm 18.6$} & $51.1 \pm 22.2$ & $<0.001$ \\
\hline TGs (mg/dL) & & \multicolumn{2}{|c|}{$112.6 \pm 50.3$} & $103.9 \pm 35.4$ & NS \\
\hline TC (mg/dL) & & \multicolumn{2}{|c|}{$114.6 \pm 44.1$} & $111.6 \pm 37.4$ & NS \\
\hline
\end{tabular}

*Data presented as mean + standard deviation or $n(\%)$. HCV $=$ hepatitis $\mathrm{C}$ virus; $\mathrm{BMI}=$ body mass index; $\mathrm{WC}=$ waist circumference; $\mathrm{ALT}=$ alanine aminotransferase; FPG = fasting plasma glucose; $T C=$ total cholesterol; $\mathrm{HDL}=$ high-density lipoprotein; $\mathrm{LDL}=$ low-density lipoprotein; $\mathrm{TGs}=$ triglycerides 
was significant difference in platelets count between $\mathrm{HCV}$ - positive cases and HCV-negative controls ( $\mathrm{P}$ value $=0.049$ ). The levels of ALT were higher in $\mathrm{HCV}$ - positive cases (Mean $\pm \mathrm{SD}=35.8 \pm 16.6)$ than its levels in HCV-negative controls (Mean $\pm \mathrm{SD}=27.9 \pm 12.4)(P<0.001)$. The levels of fasting blood glucose were higher in HCV- positive cases (Mean $\pm \mathrm{SD}=92.8 \pm 19.04$ ) than in HCV-negative controls (Mean \pm $\mathrm{SD}=86.1 \pm 12.73),(p<0.001)$. The levels of LDL i

$\mathrm{n} \mathrm{HCV}$ - positive cases were (Mean $\pm \mathrm{SD}=85.4 \pm 18.6)$ and in $\mathrm{HCV}$ negative controls (Mean $\pm \mathrm{SD}=51.1 \pm 22.2)(P<0.001)$.

b- According to Finnish Diabetes Risk Score (FINDRISC) in cases and controls: FINDRISC is used to discover persons risky for diabetes and detect the presence of the metabolic syndrome (MS). Through the study the risk was increased in HCV-positive cases, as shown in Table 2 and Figure 1.

c- According to Metabolic syndrome (MS) in both HCV-positive cases and HCV-negative controls: Overall, the anti-HCV+ subjects had a higher prevalence of MS $(26.9 \%, 36 / 134)$ than the anti-HCV-subjects $(14.1 \%, 28 / 199, p=0.004)$ (Odds Ratio=2.2), as shown in Table 3.

d- According to Metabolic Syndrome Components in both MS HCV-positive cases andMS HCV-negative controls: According to the criteria of IDF 2006 [13] that we depended on it in the diagnosis

\begin{tabular}{|c|c|c|c|c|}
\hline & Total & $\begin{array}{c}\text { HCV- } \\
\text { positive } \\
\text { cases }\end{array}$ & $\begin{array}{c}\text { HCV- } \\
\text { negative } \\
\text { controls }\end{array}$ & $\begin{array}{c}\mathbf{P} \\
\text { value }\end{array}$ \\
\hline Low risk $(<7)$ & $\begin{array}{c}161 \\
(48.3 \%)\end{array}$ & $\begin{array}{c}48 \\
(35.8 \%)\end{array}$ & $\begin{array}{c}113 \\
(56.8 \%)\end{array}$ & \multirow{5}{*}{$<0.001$} \\
\hline Slightly elevated risk (7-11) & $\begin{array}{c}121 \\
(36.3 \%)\end{array}$ & $\begin{array}{c}55 \\
(41.0 \%)\end{array}$ & $\begin{array}{c}66 \\
(33.2 \%)\end{array}$ & \\
\hline Moderate risk (12-14) & $\begin{array}{c}27 \\
(8.1 \%)\end{array}$ & $\begin{array}{c}17 \\
(12.7 \%)\end{array}$ & $\begin{array}{c}10 \\
(5.0 \%)\end{array}$ & \\
\hline High risk (15-20) & $\begin{array}{c}18 \\
(5.4 \%)\end{array}$ & $\begin{array}{c}8 \\
(6.0 \%)\end{array}$ & $\begin{array}{c}10 \\
(5.0 \%)\end{array}$ & \\
\hline Very high risk $(>20)$ & $\begin{array}{c}6 \\
(1.8 \%)\end{array}$ & $\begin{array}{c}6 \\
(4.5 \%)\end{array}$ & $\begin{array}{c}0 \\
(0 \%)\end{array}$ & \\
\hline
\end{tabular}

Table 2: FINDRISC in HCV+ Positives and HCV-Negatives subjects. of metabolic syndrome, the followings are the differences between Metabolic Syndrome Components in both MS HCV-positive cases and MS HCV-negative controls $(p<0.001)$, as shown in Table 4 .

\section{Discussion}

The prevalence of HCV antibodies is reported to be highest in Egypt [14]. Different studies have estimated the seroprevalence of HCV antibody among the general population (blood donors, mostly) to be about $0.16-6 \%$ world-wide [15]. This figure is estimated to be more than $14.9 \%$ among Egyptians [16].

Studies on MS in our locality _Upper Egypt_ are lacking, this study was conducted to clarify the prevalence of metabolic syndrome, and its components among patients with HCV in Sohag. The antiHCV positive group had a higher waist circumference (WC) (Mean $\pm \mathrm{SD}=84.3 \pm 7.8)$ with significant differences between anti-HCV positive anti-HCV negative subjects, $(p<0.001)$. It should be noted that anti-HCV positive subjects with organomegaly, ascites, or any other causes of increase intra-abdominal pressure were excluded from this study. Therefore the significant increase in waist circumference could be attributed to fat deposition, consequently could be considered as an element of metabolic syndrome. Among different scoring systems, we used Finnish Diabetes Risk Score (FINDRISC) in our study for prediction of risk of metabolic syndrome in HCV infected subjects. The performance of the FINDRISC for prevalent T2DM is comparable to other published diabetes risk scores. FINDRISC can be used as a first step tool for prediction of prevalent T2DM and metabolic syndrome. The higher the cutoff value for high risk of diabetes in the FINDRISC is used, the higher is the prevalence of T2DM found in a diagnostic test [11].

The score is usually applied on healthy population to identify diabetes risk as a part of metabolic syndrome, we aimed to use this score to assess whether the highly prevalent $\mathrm{HCV}$ infection in our community could be considered as risk factor for development of metabolic syndrome. We found significant differences between anti-HCV positive anti-HCV negative subjects, $(p<0.001)$. The data

Finnish Diabetes Risk Score

Blue: $<7$ : Low risk

Green: 7-11: Slightly elevated risk

Cream: 12-14: Moderate risk

Violet: 15-20: High risk

Yellow: $>20$ : Very high risk

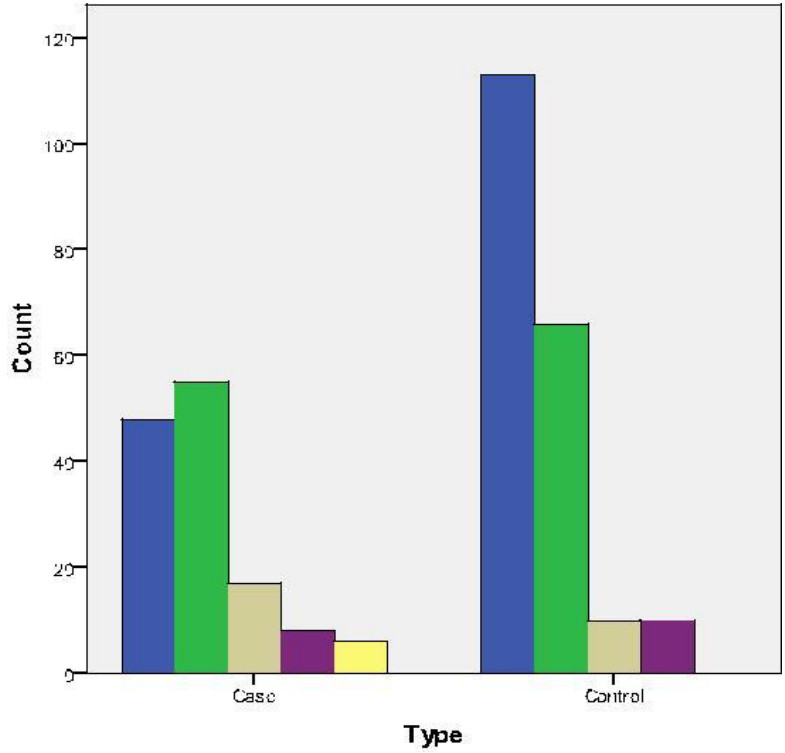

Figure 1: Relationship between cases and controls, according to FINDRISC 


\begin{tabular}{|c|c|c|c|c|c|}
\hline $\begin{array}{l}\text { Metabolic } \\
\text { syndrome (MS) }\end{array}$ & $\begin{array}{l}\text { Total } \\
\text { (333) }\end{array}$ & $\begin{array}{l}\text { HCV-positive } \\
\text { cases (134)n (\%) }\end{array}$ & $\begin{array}{c}\text { HCV- negative } \\
\text { controls (199) n (\%) }\end{array}$ & $\begin{array}{c}P \\
\text { value }\end{array}$ & $\begin{array}{l}\text { Odds } \\
\text { Ratio }\end{array}$ \\
\hline Yes & $\begin{array}{c}64 \\
(19.2 \%)\end{array}$ & $36(26.9 \%)$ & $28(14.1 \%)$ & \multirow{2}{*}{0.004} & \multirow{2}{*}{2.2} \\
\hline No & $\begin{array}{c}269 \\
(80.8 \%)\end{array}$ & $98(73.1 \%)$ & $171(85.9 \%)$ & & \\
\hline
\end{tabular}

Table 3: Distribution number of MS between HCV+ Positives and HCV-Negatives.

\begin{tabular}{|l|c|c|c|c|}
\multicolumn{2}{|c|}{ MS Components } & \multicolumn{1}{|c|}{$\begin{array}{c}\text { MS HCV- } \\
\text { positive } \\
\text { cases (36) n (\%) }\end{array}$} & $\begin{array}{c}\text { MS HCV- } \\
\text { negative } \\
\text { controls (28) n (\%) }\end{array}$ & $\begin{array}{c}\text { P } \\
\text { Value }\end{array}$ \\
\hline $\begin{array}{l}\text { HTN } \\
\text { (number) }\end{array}$ & Yes & $8(38.1 \%)$ & $13(61.9 \%)$ & \multirow{2}{*}{0.041} \\
\cline { 2 - 5 } & No & $28(65.1 \%)$ & $15(34.9 \%)$ & \\
\hline WC (cm) & $88.7 \pm 7.3$ & $85.4 \pm 4$ & $<0.001$ \\
\hline FPG (mg/dl) & $111.9 \pm 26.6$ & $102.5 \pm 20.4$ & $<0.001$ \\
\hline HDL (mg/dl) & $35.4 \pm 8.97$ & $40.2 \pm 11.5$ & $<0.001$ \\
\hline TGs (mg/dl) & $169.8 \pm 22.6$ & $164.1 \pm 30.4$ & $<0.001$ \\
\hline
\end{tabular}

Table 4: MS Components distribution in both MS cases and MS controls.

might suggest a possible role of HCV infection in the development of metabolic syndrome in our community.

Although hypertension is one of the cornerstone criteria of diagnosis of metabolic syndrome, we didn't find a significant difference in blood pressure measurements between anti-HCV positive subjects and anti-HCV negative subjects. Patients known to have DM were equally distributed between case and control groups. However when the patients underwent laboratory investigations, we found fasting plasma glucose (FPG) to be significantly higher in anti-HCV positive subjects. Such data could be a marker of insulin resistance (IR) [17]. As regard lipid profile, anti-HCV+ subjects had significantly lower HDL-C levels than anti-HCV-subjects $(p=0.004)$. Anti-HCV+ subjects had significantly higher levels of LDL-C, TGs and cholesterol than in anti-HCV negative subjects. These data are in contrast with Taiwan study in 2009 that revealed anti-HCV + subjects had significantly lower cholesterol and LDL-C levels and lower HDL-C and TG levels than antiHCV- subjects. These data are in agreement with those from previous experimental and clinical studies that addressed the association between HCV infection and abnormal lipid metabolism [7].

According to Adult Treatment Panel III (NCEP ATP III) and IDF criteria for diagnosis of metabolic syndrome in 2006, out of 333 cases and controls, 64 subjects (19.2\%) were fulfilling the criteria for diagnosis as metabolic syndrome. Overall, the anti-HCV positive subjects had a higher prevalence of MS $(26.9 \%, 36 / 134)$ than the antiHCV negative subjects (14.1\%, 28/199), ( $p=0.004)$ (Odds Ratio=2.2).

Similar data were obtained in many other studies over the world. In Taiwan 2009, a study aimed to determine the difference in prevalence and distribution of the components of MS between HCV-infected patients and healthy subjects. Multiple purpose mass screening of adults was conducted in an HCV-endemic area of Southern Taiwan. Clinical profiles in terms of anthropometric measures and MS components, as well as viral hepatitis markers, were done. Two hundred and thirty-seven adults (94 males; mean age, $55.5 \pm 10.8$ years) were recruited. The prevalence of anti-HCV seropositivity was $39.2 \%$ (93/237), regarding the age-specific distribution of MS, the prevalence of MS among anti-HCV+ subjects aged $40-60$ years was higher $(25.5 \%$, $14 / 55)$ than that of controls $(10.6 \%, 10 / 94 ; p=0.02)$. For those aged $\geq$ 60 years, the prevalence was not higher in anti-HCV+ subjects $(25.7 \%$, $9 / 35)$ compared with controls $(18.9 \%, 7 / 37 ; p=0.5)$. Subjects with MS generally have higher rates of IR and are therefore also at increased risk of developing type $2 \mathrm{DM}$, as well as future micro- and macrovascular complications [18].

Previous reports have indicated that metabolic abnormalities, including liver steatosis, obesity and DM, can worsen the course of chronic hepatitis $\mathrm{C}(\mathrm{CHC})$. In addition, $\mathrm{CHC}$ has a direct steatogenic effect on liver cells and may be involved in the development of type 2 DM. The previous study also demonstrated that the discrepancy in prevalence of MS between CHC patients and controls was inversely related to age, suggesting that HCV infection may lead to the subtle development of glucose abnormalities at a younger age. Intriguingly, the study showed that anti-HCV+ subjects had a significantly higher mean waist circumference than anti-HCV- subjects. This may somehow reflect the common observation that IR is a general feature of HCV infection. The prevalence of MS was higher in the $\mathrm{HCV}$ infected individuals $(24.7 \%, 23 / 93)$ than in the control, uninfected subjects $(13.2 \%, 19 / 144, p=0.02)$. In terms of MS components, HCVinfected subjects had a higher prevalence of high waist circumference (WC) $(51.6 \%$ vs. $25.7 \%, p<0.001)$ and hypertension $(58.1 \%$ vs. $36.8 \%$, $p<0.001)$ than controls [19].

In another study in Ohio at Case Western Reserve University, Clinical profiles in terms of anthropometric measures and MS components, as well as viral hepatitis markers, were done. Two hundred and twenty-eight adults were recruited. The prevalence of MS was higher in the HCV-infected individuals $(26 \%, 59 / 228)$ than in the control [20]. According to the criteria of IDF 2006 that we depended on it in the diagnosis of metabolic syndrome in our study, there were significant differences in Metabolic Syndrome Components between MS HCV-positive cases andMS HCV-negative controls $(p<0.001)$.

In a study in Sao Paulo 2012, the study included 125 patients infected with hepatitis $\mathrm{C}$ virus genotype 1. Metabolic syndrome was diagnosed in $21.6 \%$ of patients. Of the subjects with metabolic syndrome, $59.3 \%$ had hypertension, $77.8 \%$ had insulin resistance (IR), $85.2 \%$ were overweight, $48.1 \%$ had a high waist circumference (WC), $85.2 \%$ had an increased body fat percentage, and $92.3 \%$ had an elevated waist: hip ratio. In the bivariate analysis, female sex (OR 2.58; 95\% CI: 1.09-6.25), elevated gamma-glutamyl transferase (cGT) (OR 2.63; 95\% CI: 1.04-7.29), elevated fasting glucose (OR 8.05; 95\% CI: 3.17-21.32), low HDL cholesterol (OR 2.80; 95\% CI: 1.07-7.16), hypertriglyceridemia (OR 7.91; 95\% CI: 2.88-22.71), elevated waist circumference (OR 10.33; 95\% CI: 3.72-30.67), overweight (OR 11.33; 95\% CI: 3.97-41.07), and increased body fat percentage (OR $8.34 ; 95 \%$ CI: 2.94-30.08) were independent determinants of metabolic syndrome. Using the final multivariate regression model, similar results were observed for abdominal fat (OR 9.98; 95\% CI: 2.63-44.41) and total body fat percentage (OR 8.73; 95\% CI: 2.33-42.34). However, metabolic syndrome risk was also high for those with blood glucose $5.55 \mathrm{mmol} / \mathrm{L}$ or HDL cholesterol, $0.9 \mathrm{mmol} / \mathrm{L}$ (OR 16.69; 95\% CI: 4.64-76.35; OR 7.23; 95\% CI: 1.86-32.63, respectively) [21].

Subjects with MS generally have higher rates of IR and are therefore also at increased risk of developing type $2 \mathrm{DM}$, as well as future microand macrovascular complication [18]. Previous reports have indicated that metabolic abnormalities, including liver steatosis, obesity and $\mathrm{DM}$, can worsen the course of $\mathrm{CHC}$ [22]. In addition, $\mathrm{CHC}$ has a direct steatogenic effect on liver cells and may be involved in the development of type $2 \mathrm{DM}[22,23]$. 
Citation: Sabet EA, El Aal ASAA (2015) Hepatitis C Virus Infection and Metabolic Syndrome-A Community Based Study in Sohag University Hospital. J Diabetes Metab S13: 011. doi:10.4172/2155-6156.S13-011

However, the correlation between MS and HCV infection has rarely been investigated on basic of clinical settings. We demonstrated that subjects with HCV infection were at increased risk of developing MS and its sequels. This suggests that patients with HCV infection should be evaluated for the presence of MS, while lifestyle changes directed at increasing physical activity, optimal weight maintenance, and diet composition should be initiated.

\section{Conclusion}

In conclusion, we proved that HCV infection was associated with an increased prevalence of MS. Our data indicate a possible link between HCV infection and MS and suggest that assessment of MS in patients with HCV infection may therefore be necessary. Therefore, frequent monitoring for insulin resistance and weight gain among patients with $\mathrm{HCV}$ is beneficial because these clinical conditions can negatively affect disease prognosis and progression. Maintaining a healthy body weight is important to reduce the incidence of comorbidities and possibly delay the progression of chronic liver disease.

\section{References}

1. Hwang SJ (2001) Hepatitis C virus infection: an overview. J Microbiol Immunol Infect 34: 227-234.

2. Mastoi AA, Devrajani BR, Shah SZ, Rohopoto Q, Memon SA, et al. (2010) Metabolic investigations in patients with hepatitis B and C. World J Gastroenterol 16: 603-607.

3. Medhat A, Shehata M, Magder LS, Mikhail N, Abdel-Baki L, et al. (2002) Hepatitis c in a community in Upper Egypt: risk factors for infection. Am J Trop Med Hyg 66: 633-638.

4. Ray SC, Arthur RR, Carella A, Bukh J, Thomas DL (2000) Genetic epidemiology of hepatitis C virus throughout egypt. J Infect Dis 182: 698-707.

5. Frank C, Mohamed MK, Strickland GT, Lavanchy D, Arthur RR, et al. (2000) The role of parenteral antischistosomal therapy in the spread of hepatitis $C$ virus in Egypt. Lancet 355: 887-891

6. Grundy SM, Cleeman JI, Daniels SR, Donato KA, Eckel RH, et al. (2005) Diagnosis and management of the metabolic syndrome: an American Heart Association/National Heart, Lung, and Blood Institute Scientific Statement. Circulation. 112: 2735-52.

7. Dai CY, Chuang WL, Ho CK, Hsieh MY, Huang JF, et al. (2008) Associations between hepatitis $\mathrm{C}$ viremia and low serum triglyceride and cholesterol levels: a community-based study. J Hepatol 49: 9-16.

8. Watanabe S, Yaginuma R, Ikejima K, Miyazaki A (2008) Liver diseases and metabolic syndrome. J Gastroenterol 43: 509-518.
9. Sanyal AJ (2005) Review article: non-alcoholic fatty liver disease and hepatitis C--risk factors and clinical implications. Aliment Pharmacol Ther 22 Suppl 2: 48-51.

10. Shintani Y, Fujie H, Miyoshi H, Tsutsumi T, Tsukamoto K, et al. (2004) Hepatitis $\mathrm{C}$ virus infection and diabetes: direct involvement of the virus in the development of insulin resistance. Gastroenterology 126: 840-848.

11. Saaristo T, Moilanen L, Korpi-Hyövälti E, Vanhala M, Saltevo J, et al. (2010) Lifestyle intervention for prevention of type 2 diabetes in primary health care: one-year follow-up of the Finnish National Diabetes Prevention Program (FIND2D). Diabetes Care 33: 2146-2151.

12. Anuurad E, Shiwaku K, Nogi A, Kitajima K, Enkhmaa B, et al. (2003) The new $\mathrm{BMI}$ criteria for asians by the regional office for the western pacific region of $\mathrm{WHO}$ are suitable for screening of overweight to prevent metabolic syndrome in elder Japanese workers. J Occup Health 45: 335-343.

13. web site of the International Diabetes Federation (2006) IDF consensus worldwide definition of the metabolic syndrome

14. Shaikh FH, Ali Abro H, Ali Chhutto M, Abbasi PA, Shaikh AW, et al. (2009) Hepatitis C: frequency and risk factors associated with sero-positivity among adults in Larkana City. J Ayub Med Coll Abbottabad 21: 107-109.

15. Ito S, Yao DF, Nii C (1993) Epidemiological characteristics of the incidence of hepatitis $C$ virus (C100-3) antibodies in patients with liver diseases in the inshore area of Yangtze River. J. Gastroenterol Hepatol 8: 232-7.

16. WHO (2012) Factsheet No 164: http://googl/YcLTU, accessed at January 10 , 2012.

17. Hsieh MH, Lee LP, Hsieh MY, Tsai KB, Huang JF, et al. (2007) Hepatic steatosis and fibrosis in chronic hepatitis $\mathrm{C}$ in Taiwan. Jpn J Infect Dis 60: 377-381.

18. Carulli N (2005) Metabolic syndrome--cardiovascular disease risk and more. Aliment Pharmacol Ther 22 Suppl 2: 1-2.

19. Huang JF, Chuang WL, Yu ML, Yu SH, Huang CF, et al. (2009) Hepatitis C virus infection and metabolic syndrome---a community-based study in an endemic area of Taiwan. Kaohsiung J Med Sci 25: 299-305.

20. Hanouneh IA, Feldstein AE, Lopez R, Yerian L, Pillai A, et al. (2008) Clinica significance of metabolic syndrome in the setting of chronic hepatitis $C$ virus infection. Clin Gastroenterol Hepatol 6: 584-589

21. Oliveira LP, Jesus RP, Boulhosa RS, Mendes CM, Lyra AC, et al. (2012 Metabolic syndrome in patients with chronic hepatitis $C$ virus genotype 1 infection who do not have obesity or type 2 diabetes. Clinics (Sao Paulo) 67 219-223.

22. Moucari R, Marcellin P, Asselah T (2007) [Steatosis during chronic hepatitis $C$ : the role of insulin resistance and viral factors]. Gastroenterol Clin Biol 31 : 643-654.

23. Sheikh MY, Choi J, Qadri I, Friedman JE, Sanyal AJ (2008) Hepatitis C virus infection: molecular pathways to metabolic syndrome. Hepatology 47: 2127 2133.
This article was originally published in a special issue, Type 2 Diabetes Mellitus- Disease, Diagnosis \& Treatment handled by Editors. Dr. Judit Bene, University of Pécs, Hungary; Eun Seok Kang, Yonsei University College of Medicine, Korea 